\title{
Arguing About Goals: The Diminishing Scope of Legal Reasoning
}

\author{
Pauline Westerman
}

Published online: 14 November 2009

(C) The Author(s) 2009. This article is published with open access at Springerlink.com

\begin{abstract}
This article investigates the implications of goal-legislation for legal argumentation. In goal-regulation the legislator formulates the aims to be reached, leaving it to the norm-addressee to draft the necessary rules. On the basis of six types of hard cases, it is argued that in such a system there is hardly room for constructing a ratio legis. Legal interpretation is largely reduced to concretisation. This implies that legal argumentation tends to become highly dependent on expert (non-legal) knowledge.
\end{abstract}

Keywords Expert-knowledge - Framework directives · Hard cases · Legal argumentation · Legislation · Ratio legis · Regulation

\section{Introduction}

Usually, the study of legislation is clearly demarcated from argumentation theory. Argumentation theory is virtually unknown to those who are interested in legislation and, vice versa, legislative studies are seldom read by those who analyse legal argumentation. This relative autonomy of both fields is to be deplored. It is not wise to assume that legal argumentation remains unaffected by a change in legislative style. It is probable that the way in which rules are made has some consequences for the way judges - as well as other officials who work with rules- reason about these rules and the way they justify their decisions.

The reason I am emphasizing these obvious claims is that during the last decades there has been drastic changes in legislative style. Both at the European and at the national level of the European countries, an increasing uneasiness with rules can be observed. Rules are criticised for being cumbersome and inflexible, unable to adapt

\footnotetext{
P. Westerman $(\bowtie)$

University of Groningen, Groningen, The Netherlands

e-mail: p.c.westerman@rug.nl
} 
to rapidly changing circumstances and including 'unnecessary detail'. ${ }^{1}$ Apart from that, it has been noted that the ambition to regulate modern and complex society in detail from the vantage point of central government is bound to fail, for the simple reason that it is impossible to have the knowledge that is required for the development of such detailed rules. Central governments should rely more on local knowledge, trusting individual citizens and institutions to draft their own rules and to tailor them to their own -local- needs. As long as people are committed to achieve the goals and aims of the central legislator, they should be left free to devise the manner in which they want to achieve those aims.

These considerations gave rise to the formulation of a new type of norms, which I analysed more fully elsewhere ${ }^{2}$ and which can be captured by examining the framework directive issued at the European level. In European framework directives, substantive principal aims and policy objectives are indicated and prescribed, leaving it to the national legislatures to fill in the technical details and to enact the legislation needed in order to achieve the imposed aims and objectives. ${ }^{3}$

Interestingly, this strategy is often copied at the national level. Here as well, rough guidelines are issued in which aims and objectives are emphasized. Here as well, much of the legislative work is left to lower organs or fields of norm addressees. Finally, these lower organs, the many supervisory boards, agencies, councils and committees that are entrusted with the task of rulemaking, mirror this strategy. They also formulate objectives and targets, although these are more concrete than the purposes formulated at higher levels.

It seems then as if the framework directive serves as a kind of model for all kinds and levels of rule-making. At all levels, emphasis is on what should be achieved, rather than on how it should be achieved. The framework directive is therefore not merely a typical product of European legislation. Its technique is also used by national legislatures and affects the relations between these legislatures and their citizens. I will refer to this model of rulemaking as 'goal-regulation'.

In this article I do not directly address the question how goal-regulation in itself can be understood. Rather, I would like to inquire into how goal-regulation affects legal argumentation. Can judges still rely on their traditional toolkit of argumentative strategies? If so, to what extent? If not, why not?

My answer to these questions is neither descriptive nor prescriptive. I do not intend to either welcome or deplore goal-regulation, although the attentive reader may notice that I am skeptical about its virtues, so often extolled. Neither do I intend to merely describe judicial decision-making and the arguments invoked, although occasionally reference is made to problems that judge do in fact experience while applying this new type of goal-prescriptions. My main aim here is to give a rational reconstruction of the way this new type of norms can be interpreted and applied.

\footnotetext{
1 White Paper on Governance, Brussels, 2001.

2 See for such an analysis Westerman (2007).

3 Sometimes such framework directives are followed by so-called European 'daughter-directives' as well. The EU Water Framework Directive (Directive 2000/60/EC of the European Parliament and of the Council establishing a framework for the Community action in the field of water policy, OJ L 327 , 22.12.2000) for example has already been followed by a Groundwater Directive (2006/118/EC) to meet specific requirements of the Water Framework Directive.
} 
By exploring the peculiar characteristics of this new type of rules I will explore how a judge (or for that matter, any other norm-applier) can argue on the basis of such rules. Which argumentative strategies are simply ruled out because of the peculiar characteristics of goal-regulation? Which avenues remain accessible? And which new argumentative strategies are offered by goal-regulation? Can we point out, on the basis of a analysis of the structure of these norms alone, in which direction judicial argumentation is bound to develop? And what does that imply for the legal character of judicial argumentation? By such a rational reconstruction of what we may call 'the inner dynamic' of goal-regulation and by exploring these theoretically possible directions, some hypotheses can be developed on the basis of which further empirical research can be conducted.

But before dealing with the consequences of goal-regulation for legal argumentation, it seems wise to spend a few words on some remarkable features of goalregulation itself and how it works. This will be done in Sects. 2, 3, 4. From Sect. 5 onwards I will identify six types of hard cases that may present themselves to legal decision-makers and examine in what form they present themselves under a system of goal-regulation. This will enable me to draw some tentative conclusions in Sects. 6 and 7 concerning the scope of legal argumentation under a system of goalregulation.

\section{Features of Goal-Regulation}

As I noted above, in framework directives the goals to be reached are emphasized and it is left to the norm addressee to determine the means to be utilized in order to reach those goals. In order to see how this is done, we should examine in more detail the structure of the rules, ${ }^{4}$ such as framework directives, that prescribe such goals.

The first element to be noted then is a declaration concerning the importance of a certain aim or goal. The rule may advocate a general aim like reduction of pollution, but it may also claim the importance of a more concrete goal, such as 'the prevention of waste electrical and electronic equipment'.

Secondly, norm addressees are required to 'protect', 'ensure' or 'further' that aim. This part of the rules if often formulated as a general and extended variety of the duty of care. ${ }^{6}$ Such a duty of care is not confined to those with whom one entertains a direct relationship, but is owned to the world at large. It imposes the

\footnotetext{
4 If we confine the word 'rule' to a statement which prescribes the adoption of a certain concrete means or action in order to arrive at an-unspecified- end, the term 'rule' typically does not apply to goalprescriptive statements such as framework-directives. However, I prefer to speak of rules here, since the more appropriate alternative ('standard') sounds pretty artificial.

5 See Directive 32002 L0096 on Waste Electrical and Electronic Equipment (WEEE), 2003. This directive and its implementation in Sweden and the Netherlands are studied by Anne-Wietske Enequist in her PhD-dissertation, forthcoming.

${ }^{6}$ In the Netherlands, the duty of care is gaining importance as a general obligation to further, to ensure and to protect a certain value, or general interest. In legislative circles the duty of care is advocated as a panacea against the burdens of overregulation. See Ruimte voor Zorgplichten, report of the Ministry of Justice, July 2004.
} 
duty to care for such diverse things as the Antarctic or the well-being of cater-pillars or bank clients.

Third, norm addressees are required to draft further legislation or to take other 'appropriate measures', such as setting up inspection boards, or devising new schemes of financing. ${ }^{7}$ One may be inclined to think that this is an element that is only to be found in framework directive issued at the European level, but it should be noted that these demands are reproduced at the national level as well. Here, various national institutions or supervisory boards are required to make rules. The Dutch Act on Quality of Health Care Institutions (1996), ${ }^{8}$ for instance, is no longer confined to 'hospitals' - as was the old Act-but addresses all those who are involved with health care, including private institutions. In this act it is asserted that these institutions themselves are held responsible for providing good care. Central government is only responsible 'at a distance'. The aim of good care is specified in three criteria (care should be effective, efficient and patient-oriented), but since every institution 'has its own objectives', it should tailor the rules to their own specific needs and objectives. ${ }^{9}$ The Act obliges these health care institutions to formulate these more specific objectives, to translate them into performance indicators, to set up standards and protocols and to draft a system of quality control.

Fourth, norm addressees are required to report on the measures they have adopted and the rules they have drafted. In the Council Directive on Health and Safety at Work, ${ }^{10}$ for instance, member-states are required to communicate the text of the provisions of national law to the Commission and to report every five years on their practical implementation. Norm addressees are here required to prove that they complied with the norms that oblige them to achieve aims and devise means. Health care institutions are required to regularly monitor and evaluate the rules and protocols they drafted, and to report all this to an inspection agency.

Summarizing, this new kind of rules consists of the following elements:

1. 'Abstract aim A is valuable'

2. 'Further aim A'

3. 'Draft rules or devise other means appropriate to achieve aim A'

4. 'Report on progress'

\section{Two Ways to Make Goals Concrete}

The above-mentioned elements 1-4 cannot be studied in isolation. They belong together. One never comes across a rule which confines itself to the prescription of an aim. The freedom to devise means conveyed by 3 is always accompanied by the requirement that norm addressees should report. Moreover, these clusters of

\footnotetext{
${ }^{7}$ WEEE-directive Art.6.2.

${ }^{8}$ Kwaliteitswet Zorginstellingen.

${ }^{9}$ Bulletin concerning Act on Quality of Health Care Institutions, Ministry of Health, Welfare and Sport, 1996.

10 89/391/EEC, 12 June 1989.
} 
elements 1-4 reproduce themselves at lower levels of organization. Not only do national legislatures faithfully copy the structure of the European framework directive, but national institutions, such as supervisory boards, can also be seen to issue such goal-prescriptive rules. They require museums, universities and swimming-pools to formulate goals or objectives, to translate them into rules or protocols and to report on the progress that is made.

This implies that the system of goal-regulation is reproduced at different organisational levels. Goal-prescriptive rules are issued at more central and more local levels. How this is done can best be illustrated by means of a schematic representation of rulemaking as it is carried out in environmental law. Here we can trace the way in which aims are translated into more concrete goals and these goals into more concrete objectives by different levels of rule-makers. At each level of concretization, the structure of this new type of rules is discernible. At each level elements 1-4 distinguished in the previous section, recur. Elements 1 and 2 are often combined in the sense that the importance of the aim is immediately followed by the statement that the goal should be realized or furthered, or where the importance of the aim is tacitly implied in the admonition to further the goal. The other two elements recur separately.

(1a) Further the protection of the environment.

(1b) Make sure that you take the necessary precautions, draft the necessary legislation

(1c) Report on the progress you made

(2a) The emission of toxics should be as low as reasonably achievable.

(2b) Make sure you carry out a feasibility study, take the necessary measures, including rule-making.

(2c) Report on the progress you made.

(3a) Within 2 years emission of toxics should be reduced by $10 \%$

(3b) Inquire into the 'best available techniques'. 11

(3c) Report on the progress you made.

From this example we can see that each level not only represents a more local level of organisation, but also a more concrete version of the goal at hand.

Two kinds of concretisation should be distinguished. The first form consists of the analysis of a more abstract goal into its component parts. The goal at (1a) (protection of the environment) is at the lower level (2a) translated into the more concrete 'reduction of emission of toxics'. Evidently, this is not the only concretisation that takes place. 'Preservation of flora and fauna' is another one. And each of these concretisations gives rise to endless more refined and more concrete versions. But all these more and less concrete versions of goals figure at level (a) of more concrete goal-prescriptive rules issued at lower levels.

It is always possible to classify goals as 'means' and it is especially tempting to regard concrete goals (the preservation of a specific bird species) as a means to a more abstract end (the preservation of fauna). There is nothing wrong with that. For the external observer concrete goals can be reconstructed as means (and means can

\footnotetext{
11 The so-called BAT-principle, often invoked in environmental law.
} 
be seen as goals). We should keep in mind, however, that such concrete goals do not figure as means for those who are addressed at this level. For them the concrete goals they are required to achieve figure as goals and not as means to be utilized. On the contrary, the rule requires them to determine those means. In order then to achieve the goal of preservation of a specific bird, they have a certain-not unlimited- freedom of choice. They may decide to subsidize farmers for not mowing the grass, or they may opt for a strict prohibition to enter specific areas etc.

The second kind of concretization consists of determining the extent to which a certain aim -or its component part- should be realised. In the adduced example this happens in the transition to (3a). Here the overall aim is concretised in targets to be reached and these targets should be conceived as bus-stops along the road to the desired end-state. These bus-stops are goals 'for the time being'. As soon as they are reached these bus-stops are substituted by more ambitious ones, closer to the intended end. Also these bus-stops are goals. They do not indicate the means to be deployed. Again, the means are left to be specified by the norm addressees.

\section{No Divergence between Rule and Purpose}

The novelty of goal-regulation is not that the rules are vaguer or more abstract than traditional rules such as 'no vehicles in the park'. At lower levels these rules can be immensely concrete. They stipulate the amount of arrests that should be made by the police, or they fix the allowed waiting-time in the emergency units of hospitals. But they determine outcomes, not means. How the police should reach the target is not stipulated by such rules. And if some smart hospitals reduce waiting-time in the emergency unit by putting patients on stretchers in the corridor, there is nothing in the law that prohibits such a course of action, although such interpretation of the rule may be criticised. ${ }^{12}$

In this respect goal-regulation can be understood as a complete reversal of the traditional state of affairs, in which rules fix and prescribe a certain course of action to be followed in order to reach a certain goal. The examples that are usually analysed by philosophers of law are of this type. 'No dogs allowed', just as 'no vehicle in the park', or 'a will should be signed by three witnesses' typically prohibit or prescribe actions and these actions are means in order to reach an -often largely unspecified- goal. Whether the prohibition of dogs is meant to contribute to hygienic surroundings or to the reduction of noise is therefore mainly a matter of interpretation. ${ }^{13}$ In goal-regulation that relationship is reversed. The goals are fixed and the means are left undetermined.

That implies that the literature concerning how we should deal with discrepancies between means and ends is no longer applicable to goal-regulation. In a traditional regulatory landscape where means are fixed, rule-following can be counterproductive.

\footnotetext{
12 See Hood (2006), Julia Black, interestingly, notes a paradox here. Although the emphasis on goals is meant to commit citizens to certain values 'beyond' the law, the indeterminacy of means may generate more rather than less calculative behaviour. See Black (2008) at p. 33.

13 Schauer (1991).
} 
We could say, for instance, that the person who waited for a red traffic light while transporting a fatally injured passenger has acted as a rigid formalist who had failed to 'see through' the letter of the law. Or, if we argue the other way round, we may speak in favour of formalism by saying that, in general, sticking to the rules is justified since it increases efficiency, predictability, and fairness, even if in particular instances norm-conformity has consequences which are at odds with the underlying purpose of the rules. But both formalists and pragmatists start from the assumption that there is a certain distance between a rule (indicating and prescribing the means) and its purpose. In some cases that distance generates a tension which is debated by the theorist and decided -one way or another- by the practitioner.

This distance and in some cases even tension between rule-following and the achievement of goals has disappeared in the type of rules that are drafted according to the model of the framework directive. For here, following a rule is identical to achieving an end. One can only be said to have conformed to the rule if the end which is prescribed by that rule (element a) is successfully achieved. If the normaddressee has taken the steps required by element (b) ('draft the necessary rules', or 'take the necessary steps') but failed to achieve the goal prescribed by (a) he cannot be said to have fulfilled the rule since the rule does not merely require him to take any steps, but to take the appropriate steps. And this norm is not fulfilled by the hospital-director who attempted but did not succeed in reducing waiting time. So although in practice there may arise controversy on the matter whether certain steps and measures are appropriate to the imposed end, the rule itself is formulated in such a way that there is no divergence between norm-compliance and goalachievement, as is the case with the car-driver who waited for the red light and failed to rescue the life of his passenger (or, vice versa with the car-driver who rescued his passenger but violated the traffic rules). Whoever failed to further the goal, ipso facto violated the rule.

\section{Six Types of Hard Cases}

So in goal-regulation there is no tension between following rules and achieving aims. Compliance is identified with -successful- performance. This has important consequences for judicial argumentation.

In order to find out what these consequences are, I think it is worthwhile to focus on so-called 'hard cases', where the link between the facts and the rules is problematic. The use of the term 'hard case' is controversial. Some legal theorists claim that in fact all cases are 'hard' or difficult to solve since no case is unequivocally covered by 'the' relevant rule in a mechanical manner. They claim that the apparent ease with which we apply the rule that 'vehicles are not allowed in the park' to this particular Volvo in the flowerbed is illusionary. ${ }^{14}$ That ease is always the product of prior interpretation in which either the facts (this is an ordinary car; it is not an exhibition-piece nor a war memorial) or the rules (by 'park' such and such area is understood) or both are interpreted. Others maintain that the

\footnotetext{
14 Kennedy (2001).
} 
majority of cases are easy to solve; the hard ones only appear at the fringes of the domain covered by rules. ${ }^{15} \mathrm{I}$ do not intend to engage in this debate here. Even if we agree that all cases are 'hard' we can nevertheless discern differences in the amount of legal argumentation involved and that is what I want to explore in this article. Some cases apparently call for more elaborate argumentation than others. Since I am interested in the consequences of goal-regulation for legal argumentation, I think it is wise to draw attention to such cases rather than to the Volvo-like cases which are usually argued sparsely, by a mere reference to 'the' relevant rule.

There are two sets of problems that turn cases into hard cases and which call for more elaborate legal argumentation than the easy ones. The first set concerns difficulties that have to do with the incomplete or imperfect coverage of facts by rules. Here, three possibilities present themselves.

1. There is no rule covering case $C$

2. There is no clear rule covering case $C$

3. There are two conflicting rules covering case $C$

The second set of difficulties arise where despite the availability of a clear rule covering the case, it is deemed undesirable to apply that clear rule to the specific case at hand. ${ }^{16}$ The following possibilities present themselves:

4. There is a clear rule for case C but we do not want to apply it to this particular case because application would entail consequences that conflict with the underlying aim of the rule itself

5. There is a clear rule for case C but we do not want to apply it to this particular case because application would entail consequences that conflict with the underlying aim of other rules

6. There is a clear rule for case C but we do not want to apply it to this particular case because application would entail consequences that conflict with interests, principles or aims not instantiated by any rule at all.

I do not pretend to have exhausted all possibilities, but presumably these six possibilities cover a large area of the hard cases that present themselves to legal decision-makers. We should be aware that these six possibilities cannot be distinguished and labeled as neatly separated categories. Often the undesirability of application is masked as unavailability of the rule, as is the case if a judge argues that a clear rule is lacking in order to hide from view that he thinks that a certain existing rule would entail undesirable consequences. It is possible to turn a seemingly easy case into a hard one and vice versa and it is also possible to turn a specific type of hard case into another one. ${ }^{17}$ But that is not what I am interested in here. I am now mainly interested in the way goal-regulation affects legal argumentation. Let me therefore examine the six possibilities one by one.

1-There is no rule covering case $C$

\footnotetext{
15 Hart (1961).

16 Hage and Visser (1997).

17 Kennedy (1997). See also Feteris (2005).
} 
This type of hard case seems to be unaffected by goal-regulation. Obviously, it is still possible that large areas of human activity, especially new activities that have to do with technological developments, are not covered by rules. Probably, the absence of such rules indicates the absence of a more abstract framework directive by which abstract aims are imposed. At this very moment, for instance, there is no abstract duty of care imposed on Internet providers. There are no lofty aims formulated that may function as a starting-point for an extensive set of more concrete rules. Those unregulated areas may be decided by means of analogy and these analogies may be drawn from ordinary rules but also from other abstract goal prescriptive rules. There is nothing that impedes judges, for instance, to invoke a duty of care for Internet providers, analogous -and on good grounds comparable- to other duties of care. These analogies do not only help the judge to arrive at decisions, but can also play a role in the argumentation by which these decisions are justified.

\section{2-There is no clear rule covering case $C$}

As for possibility two, the absence of clear rules may be attributed to omissions on the part of lower echelons to further concretise the goals that were transmitted to them by means of a framework directive. A European directive may not have been (fully) implemented, or the director of the hospital may have failed to develop a certain protocol. In itself these omissions may be a reason for a judge to apply a sanction, especially in those cases where the more abstract rule imposes the obligation (element b) to draft precise rules.

It seems, however, that in the absence of more concrete rules, the judge has no alternative than to decide according to the merits of the case, as he is used to do. In doing so, he will be guided by the more abstract framework directive that had imposed a general duty of care or by a general precautionary principle. However, both such a principle as well as the duties of care are formulated in highly aspirational terms. They are not like rules that you can either comply with or violate. The digital yes/no structure is supplanted by a gradual slope, which is well expressed in those framework directives which require norm-addressees to maximize the well-being of their employees or to protect the Antarctic. The judge will then have trouble to estimate the degree in which a certain firm or explorer has fallen short of this ideal. In other words, he will see no other alternative than to engage in what I called this second task of concretisation, which consists in determining bus-stops: assessing the extent in which a certain aim should be realized. The judge has to determine a zero-line.

This amounts to a lot of deliberation and consultation, but involves no legal reasoning. The judge is not deliberating on the scope, weight or applicability of a certain legal standard but has to rely on technical standards. In environmental law, for instance, the judge has difficulty in applying the above-mentioned BAT-norm, which is highly aspirational. In order to determine whether the defendant violated that norm or not, he has to take into account the level of techniques that is commonly employed by comparable industries. The judge has to resort to results of bench-marking carried out by local experts. ${ }^{18}$ His decisions are therefore informed by the expert information on the state of the art rather than sustained by legal

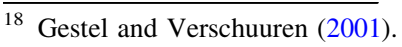


standards. The arguments that justify his decision will then either refer merely in a short-hand way to the vague and aspirational standard, in which case argumentation is defective and uninformative or will make use of these expert reports in which case argumentation can no longer be called legal. ${ }^{19}$

\section{3-There are two conflicting rules covering case $C$}

In a system of goal-regulation, the possibility of two -or more- conflicting rules is not diminished but increased. The reason for that is that most rules are developed by local or lower echelons, boards and committees which are often especially designed and instituted to further and implement the goals in a certain area. As pointed out elsewhere $^{20}$ all those bodies, boards and committees who are drafting and developing rules in order to improve for instance labour conditions necessarily lack the required bird-eye view that would enable them to balance good labour conditions with other aims (innovative economy, good health care). Norms that prescribe the attainment of the component parts of aim A may and often do conflict with norms that prescribe the attainment of the component parts of aim B. Here, the judge is required to engage in his traditional role of weighing interests and aims as they come to the surface in this particular case. Goal-regulation does not seem to affect the way the judge may deal with these three difficulties, although the fact that the various conflicting goals are formalized in law may give them more weight and a more 'objective' status. ${ }^{21}$ The only difference brought about by goal-regulation is that such conflicts are more widespread than ever and inevitably linked to the way these rules are produced.

Summarizing, we should say that goal-regulation mainly seems to affect the way remedies are sought for the problem (2) where clear rules are lacking. In order to remedy this problem, judges mainly rely on expert knowledge pertaining to the usual level of performance that is common in a certain area or in comparable circumstances. As for problem (1) and (3), however, the judge may stick to his traditional role.

The second set of difficulties I discerned above, is different from the first set of problems, since they simply do not present themselves in these terms in a landscape marked by goal-regulation. The reason is of course, that all talk of 'underlying aims' is nonsensical in the case of rules who oblige the norm-addressee in a direct and explicit manner to achieve a certain aim. There are no underlying aims, but the aims are the subject-matter of the rules.

Now this seems a very trivial remark. If we turn once more to the example in which the successive stages of rule-formation are illustrated, we see that the concrete aim of a $10 \%$ reduction of emission of toxics is indicated by the rule at level (3a) itself, but this aim is a more concrete version of the more abstract aim 'reduction of toxics' that figures at (2a). That means that we can still sensibly speak

\footnotetext{
19 If we understand by 'legal argumentation' something more than argumentation put forward by a legal official.

20 See Westerman (2007).

21 See Barak (2005). Although these conflicts between goals would not qualify as being subjected to 'interpretation' in Barak's - narrow- sense of the word since these goals figure in different texts.
} 
of 'underlying aims'; referring to the more abstract aim that was at the cradle of the more concrete aim. The underlying aim of (3a) is expressed by (2a); the underlying aim of (2a) is (1a) and so on.

Let us see where this redefinition of the term 'underlying aim' leads us and examine the three possibilities one by one.

4-There is a clear rule for case C but we do not want to apply it to this particular case because application would entail consequences that conflict with the underlying aim of the rule itself

If we translate this difficulty in a vocabulary which does justice to the specific nature of goal-regulation we should say that

4. There is a clear rule for case C prescribing a concrete aim, but we do not want to apply it to case $C$ because application would entail consequences that conflict with the more abstract aim from which the concrete aim is derived.

The judge may acknowledge the state of affairs to be like this. In theory it is possible that the judge does not apply a concrete rule because it conflicts with the more abstract aim from which it is derived. However, in practice, such a decision is beset with difficulties.

In the first place, we should recall how concrete aims are 'derived' from abstract aims. As I noted in the beginning, this derivation (I called it the first kind of concretisation) is no more than the analysis of abstract aims into more concrete ones, which are thought of as component parts of the more abstract aims. The reduction of toxics (2a) is therefore not a fallible means to achieve the more abstract aim of clean environment, but the clean environment is defined as consisting in reduction of toxics in the first place. A judge who decides that the concrete aim should be outweighed by the more abstract aim, in fact sets out to assert that a clean environment does not consist in a reduction of toxics. Such a judge does more than deciding a case. He is even doing more than legislating, which is traditionally speaking nothing more than devising rules as means to achieve ends. He is questioning the very building blocks of the abstract aims themselves. Building blocks that had been distinguished and analysed by -mainly- experts in the field. In any case, if he justifies his decision by questioning these building blocks as component parts of more abstract aims, he is not engaging in legal argumentation. $\mathrm{He}$ is doing the work of the expert and argues on the basis of non-legal standards.

5- There is a clear rule for case $C$ but we do not want to apply it to this particular case because application would entail consequences that conflict with the underlying aim of other rules.

Translated into the vocabulary appropriate in goal-regulation this difficulty can be reformulated as:

5. There is a clear rule for case C prescribing a concrete aim, but we do not want to apply it to case $C$ because application would entail consequences that conflict with a more abstract aim from which other concrete aims are derived.

This sounds pretty artificial and farfetched, but it is not. We may think here of the case that would arise if a hospital had taken the labour regulations so seriously that it would no longer admit severely handicapped persons as patients, since their treatment would impair the labour conditions of the nurses. The judge may rule in such a case that the clear rules pertaining to labour conditions should not be applied 
without further ado but should be weighed carefully against the well-being of handicapped patients.

In this kind of hard case the judge is allowed a bit more freedom than in possibility (3) since he is permitted to escape from the narrow confines of sectoral divisions ordered around a single abstract goal and its more concrete deductions. He is allowed to look at other aims. However, we should note that the judge has to rely on aims that are expressly posited and clearly established. This marks a difference with his traditional role. As I noted above, the classical rule does not express goals to be achieved but prescribes a concrete manner by which these goals can be achieved. Sometimes this means-prescription is accompanied with an explicit reference to the goal that is hoped to be achieved by such a rule. Those references can be found in explanatory notes stated at the beginning of the text of an Act. In such cases, the judge may argue on the basis of such explicit aims. This argument is then the result of so-called 'historical interpretation', i.e. interpretation of the meaning of legislative intent.

Often, however, such explicitly stated goals are absent. The rule may for instance be understood as serving several (implicit) goals at the same time; or the rule may be understood as embodying a compromise between divergent goals. As I pointed out in Sect. 4, many traditional rules of the type 'no dogs allowed' specify means but leave the goals unspecified. Judicial decision-makers are then enabled to attribute or ascribe goals to such rules. Confronted with hard cases they try to 'invent' an underlying reason: to construct a ratio legis which is not (yet) fully articulated but which may give sense and unity to a system or area of law.

Such room for rational reconstruction is not available to those who have to decide in an area permeated by goal-regulation. They have to conform to aims that are proclaimed to be the aims and which are as such codified and imposed by all those bodies that are engaged in rulemaking. In other words: most of the teleological interpretation necessarily turns into historical interpretation, focusing on the aims and purposes of the various legislators involved. This limitation affects the kind of arguments that are put forward as justification for decisions. Only explicit aims have justificatory power. But although these justificatory arguments may only refer to explicitly mentioned aims, they can -and probably should- nevertheless give reasons why one aim was considered to be more weighty than the other one(s) and how a balance should be struck.

6-There is a clear rule for case C but we do not want to apply it to this particular case because application would entail consequences that conflict with interests, principles or aims not instantiated by any rule at all.

This difficulty can be translated as:

6. There is a clear rule for case C prescribing a concrete aim, but we do not want to apply it to case $C$ because application would entail consequences that conflict with interests, principles or aims not concretised in any rule at all.

Here at last, there is room for a rational reconstruction of the kind that was found wanting under 5 . Here, the judge is not confined to stick to officially proclaimed aims, but may invent and construct aims that are not yet (fully) formalised and codified. It should be noted, however, that this room for legal interpretation is rapidly diminishing. In a system of goal-regulation goals are made explicit and 
fixed. We can understand that process as the formalisation and -at timesstandardization of (abstract and concrete) goals. That means that legal argumentation is often restricted to the kind of arguments allowed under (5) that refer to formailzed and explicitly mentioned goals.

Summarizing, we may note that the judge can only fully engage in the interpretive activity of inventing a ratio legis in those cases where aims are not yet formalised. Only there, the arguments put forward in order to defend judicial decision-making may contain allusions to tacit goals and principles that can be thought to make sense of existing rules. In possibility (5) where application of the rule conflicts with the more abstract aim of another set of rules, the judge is not allowed to engage in this kind of teleological interpretation but should stick to some kind of historical interpretation, referring to the intent of the (different kinds of) legislators and regulators. As for the possibility to reject application of a rule prescribing a concrete aim on the ground that it conflicts with its more abstract ancestor, (possibility 4) his freedom is curtailed by the legislative activities of -mainly- experts in the field.

The consequence of this diminishing room for freedom in constructing -implicitgoals is that judicial argumentation tends to lose innovative power. The 'invention' of a ratio legis and the defense of such a ratio legis in legal argumentation allows for the discovery and subsequent development of new topoi and new perspectives; not only on the question what valid law is, but also on the values and aims it (should) serve. If we see legal argumentation in the wider context of a collective enterprise, as a discourse of justification and criticism, we come to appreciate its role in discovering and proposing desirable aims and values. If this discourse is for a large part confined to the aims that are prescribed and formalized by legislators and regulators, it will no doubt become impoverished in the long run.

\section{Recourse to Non-Legal Arguments}

The last three categories of hard cases had to be translated into a different vocabulary, using terms like 'more abstract' and 'more concrete' aims, in order to do justice to the fact that in a system of goal-regulation the aims are fixed and the means are left free to be determined. The translation helped us to gain some insight in the scope of legal argumentation that is made possible under such a system, but in fact ignored the fact that, basically, matters are reversed in a system of goalregulation. I noted in par. 4 that there is no longer a divergence between rulefollowing and the achievement of goals, because rule-following implied ipso facto the achievement of goals. The only kind of discussion, therefore, to be conducted is about whether concrete goals are the right ingredients or component parts of more abstract goals. But that is largely a matter for experts to decide upon. Whether reduction of emission of $\mathrm{CO} 2$ is a component part of 'reduction of pollution' is a question that does not require a legal answer, but a technical one. The same applies to the question whether health at work can be analysed as consisting of ' 6 hours on end at the computer screen' or '3 hours'.

So it seems that in a system of goal-regulation the interesting problems are not about the aims to be pursued -these are fixed and authoritatively determined at both 
abstract and concrete levels-, but about the means to be employed. The case of the cunning hospital is a good example. Imagine that one of those patients, put on stretchers in the corridor in order to reduce waiting time, dies of a heart attack and charges are pressed on the hospital. Is it of any help if the judge would inquire into the 'underlying or more abstract aims'? Not at all. The concretisation of aims is impeccable. The larger aim of good health care is split into various more concrete aims, one of which is a short waiting time. The hospital -together with other hospitals and supervisory boards- has developed a criterion, allowing no more than 1 hour waiting time. What is more, it has reported that indeed it succeeds to achieve that target. The only sensible criticism then is not about the aims to be pursued. It is about the means employed. To put patients on stretchers is not the proper method to reduce waiting-time. But although we may blame the hospital for choosing the wrong means, it cannot be blamed for not following the rules. On the contrary, its mistake had precisely been that it had taken too seriously the concrete aim of the waiting-time rule.

There are two options left. The first is to say that the hospital is to be blamed for deciding on the wrong means. This option can be defended but we should note here that we cannot say that the hospital is legally wrong. If the judge decides in this manner, he cannot use legal arguments. He either has to rely on his own wits or on expert advice. The second option is to say that it had been wrong to establish the waiting-time rule. The choice of this particular component part of 'health care' had been unfortunate and leads to perversion. Again, such an argument is not a typically legal one. If the judge uses such an argument, he criticises the work done by the lower level rule-makers. Much of that work is, again, carried out by experts.

The example sheds some light on the scope of legal argumentation within a context that is dominated by goal-regulation. In a system that fixes ends and leaves the means undetermined, a lot of attention will have to be paid to the suitability of the means deployed. But if the judicial decision-maker has to judge that suitability, he can no longer rely on a set of legal rules regulating actions as means to be deployed. Rather he is compelled to engage in a kind of free floating assessment of the propriety of the actual means and actions that are chosen by the norm addressee in order to achieve the imposed aims. In such an assessment he is hardly bound by legal considerations and has to rely on expert knowledge or the information provided by those 'in the field'.

\section{Conclusion}

Goal-regulation can be understood as an attempt to make explicit and to formalise the goals that should be achieved. This is done by prescribing the achievement of goals and leaving it to the norm addressees to concretise these goals into ever finer and more concrete goals and targets to be reached. The process of concretisation consists of two activities. In the first place, the more abstract goals are analysed and split up into component parts. In the second place, these component parts are endowed with criteria indicating the extent to which the imposed goal should be realized. Both activities are carried out by organisational subunits, and at each 
successive level a component part of the original goal is prescribed and attached to a general obligation to devise the means necessary to achieve those goals. These means may refer to direct measures and actions, or to further rulemaking. If the latter option is chosen by the lower echelon, the strategy of formulating and prescribing goals is often mirrored and reproduced at a more concrete level.

In this article I tried to assess the consequences of goal-regulation for legal argumentation. In some respects that scope remains unaffected. If the judge is confronted with cases in which rules are lacking or conflicting, his arguments have to refer to the reasons that are relevant to a kind of balancing and deliberation that is quite similar to the kind of reasoning practiced in an ordinary legal landscape. If he is confronted with vague rules, (prescribing abstract aims that can be realised to a larger or smaller degree) he will have trouble in establishing criteria and has to rely largely on expert knowledge.

As for those difficulties that arise if applicability of available rules is deemed undesirable because consequences of application run counter to underlying aims, we should be aware that these difficulties do not exist as such since there are no 'underlying aims' of rules which prescribe precisely the achievement of those aims. If we understand those difficulties as clashes between concrete aims and more abstract aims, legal argumentation seems to be reduced to references to formalized and fixed aims, instead of revolving around a ratio legis as the product of legal reconstruction. Such argumentation cannot suggest other lines of inquiry and cannot propose alternative perspectives. The room for legal argumentation is only unaffected in those areas where goals are not (yet) fixed and established. Finally, it has been noted that since in goal-regulation the means are left free and the goals are fixed, most of the interpretative work to be done by decision-makers consists of the assessment of the suitability of the means employed. However, in order to assess those means no legal knowledge and no legal argumentation are required. The conclusion seems to be justified that the judge will increasingly be dependent on expert knowledge that is mainly present in the specialized areas involved.

Open Access This article is distributed under the terms of the Creative Commons Attribution Noncommercial License which permits any noncommercial use, distribution, and reproduction in any medium, provided the original author(s) and source are credited.

\section{References}

Barak, A. 2005. Purposive interpretation in law. Princeton: Princeton University Press.

Black, J. 2008. 'Forms and paradoxes of principles based regulation', LSE Law, Society and Economy Working Papers 13/2008, http://ssrn.com/abstract=1267722.

Feteris, E.T. 2005. The Rational reconstruction of argumentation referring to consequences and purposes in the application of legal rules: a pragma-dialectical perspective. Argumentation 19: 447-459.

Gestel, R. van, and J. Verschuuren. 2001. Alara: minimumregel of beginsel met aspiraties? In: P.C. Gilhuis en A.H.J. van der Biesen, eds. Beginselen in het milieurecht, Deventer.

Hage, J., and M. Visser. 1997. Voorwaarden van regeltoepassing. Rechtsfilosofie \& Rechtstheorie 26/3: 196-212.

Hart, H.L.A. 1961. The concept of law. Oxford: Clarendon Press.

Hood, C. 2006. Gaming in targetworld: the targets approach to managing British public services. Public Administration Review 66(4): 515-521. 
Kennedy, D. 1997. A critique of adjudication [fin de siecle]. Cambridge: Harvard University Press.

Kennedy, D. 2001. The political stakes in "merely technical" issues of contract law. European Review of Private Law 9(1): 7-28.

Schauer, F. 1991. Playing by the rules: a philosophical examination of rule-based decision-making in law and in life. Oxford: Clarendon Press.

Westerman, P.C. 2007a. The emergence of new types of norms. In Legislation in context: essays in Legisprudence, ed. J.W. Luc, 117-133. Aldershot: Ashgate.

Westerman, P.C. (2007). Governing by goals: governance as a legal style. Legisprudence: International Journal for the Study of Legislation 51-72, Hart Publishing. 